\title{
NUMERICAL MODELING OF SKEW ROLLING PROCESS OF TWIST DRILLS
}

\author{
Tomasz Adam Bulzak' ${ }^{1}$ Zbigniew Pater', Janusz Tomczak' \\ 1 Faculty of Mechanical Engineering, Lublin University of Technology, Nadbystrzycka 36 St., 20-618 Lublin, \\ Poland, e-mail: t.bulzak@pollub.pl
}

Received: 2016.07 .28

Accepted: 2016.10.08

Published: 2016.12.01

\begin{abstract}
This paper presents the results of numerical modeling of skew rolling process of twist drills in four-segments configuration. On the basis of the conducted numerical simulation the results were obtained in a form of distributions: stress intensity, strain intensity, temperature and damage. The energetic parameters of the process were also given on the example of a drill $\varnothing 10 \mathrm{~mm}$ from high-speed steel HS6-5-2. The conducted numerical simulation confirmed the usefulness of the graphic method based on envelope theory in tools designing for skew rolling of twist drills.
\end{abstract}

Keywords: skew rolling, FEM, twist drill.

\section{INTRODUCTION}

Twist drills applied for manufacturing of cylindrical holes are tools used in various industrial branches [6]. As Bulzak et al. [2] state, forming of helical outline of drills is realized by machining and metal forming methods. In the case of machining, drill helical outline is obtained during milling and grinding. For manufacturing of twist drills by means of metal forming are mainly used extrusion and different types of rolling process.

Skew segment rolling is the process which, due to its advantages, is widely applied for manufacturing of twist drills on the whole world. This process is respected among drills producers mainly thanks to: high efficiency, savings of tool steel, simple construction of devices for rolling and tools. The efficiency of the skew rolling process for drills of diameter $\varnothing 10 \mathrm{~mm}$ equals almost 200 pieces per hour. Wear of tool steel in this process is almost $30 \%$ smaller than in the case of milling or grinding. Costs of machining tools manufacturing by means of rolling methods are considerably smaller than in the case of milling. The limitation of the skew rolling process is maximal diameter of the rolled drills. The drill's proper geometry is achieved rolling drills of diameter not exceeding $20 \mathrm{~mm}$. Above this diameter the drill forging has rounded edges, which cause lowering usable property of twist drills.

At present, manufacturers of machines for skew rolling admit that in their offer they have machines which allow for rolling of drills of maximal diameter not exceeding $23 \mathrm{~mm}$, which constitutes maximal diameter for this process. In Poland, under the direction of prof. Olszewski from Metal Forming Institute in Poznań, a process of manufacturing drills with dimensions above $23 \mathrm{~mm}$ was worked out, which is based on initial rolling of the drill outline and grinding. Connecting rolling and grinding operations increased precision of manufactured drills with larger diameters and decreased wear of toll steel. Under the direction of prof. Olszewski also a method of manufacturing drills with larger diameters rolling was worked out, which is based on rolling a simple drill profile in two roll passes and torsion. The advantage of this method is, by no means, the fact that all three operations are realized by applying one device.

The idea of skew segment rolling of twist drills is shown in Figure 1. Forming of drill helical outline is realized by means of two pairs of 


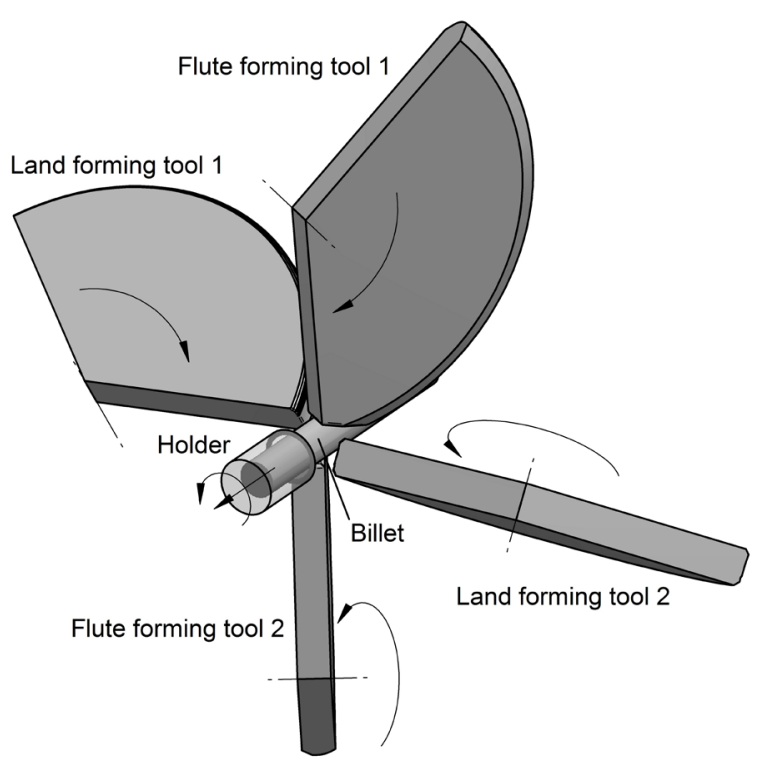

Fig. 1. Schema of skew segment rolling process of twist drills

rollers which rotate in opposite directions. One pair is used for forming flutes, the second one is used for forming lands. Tools are placed in relation to the rolled product axis at angle a few degrees larger than inclination angle of drill helical line. The drill forming starts from the holder part and gradually proceeds to the end of drill's working part. The drill outline in the skew rolling process is achieved in one cycle. Tools used for drills rolling have a simple design and in rolling configuration make close impression corresponding to the drill outline. The only problem present during tools designing is working out their correct shape. The shape of tools working parts used for twist drills forming constitute the drill envelope, which are flutes and lands.

For the numerical analysis needs, tools shape was determined by graphic method based on envelope theory, which was described by e.g. Ivanov and Nankov [4]. This method is also applied for designing tools for milling of twist drills. Skew rolling processes are widely spread in machine industry, which is conditioned by numerous advantages of these metal forming processes. The main advantages include: high efficiency, material savings, high precision of formed elements and low manufacturing costs. As Zhang [7] assumes, skew rolling processes can be used for manufacturing of wide range of products: balls, bearings rings, pipes, bushes, axi-symmetrical forgings and preforms.

\section{DESIGNING OF TOOLS OUTLINE FOR SKEW ROLLING OF TWIST DRILLS}

In the skew rolling process of twist drills are present problems identical as in the case of flutes grinding. The flute outline during grinding is a resultant of grinding wheel geometry and relative motion between the grinding wheel and machined material. In the case of grinding there are two designing methods, which are schematically presented in Figure 2. The differences between these methods, according to Karpuschewski et al. [5] result mainly from the type of applied grinder. The direct method can be applied for designing grinding process on multi-axes grinders, yet, the indirect method is applied for designing grinding processes on conventional grinders or grinders with smaller kinematic possibilities. In the direct method for flutes forming are used grinding wheels of standard outline. Obtaining appropriate shape of flute is connected with determining appropriate position of the grinding wheel and appropriate defining kinematics of the machined element and tool. Grinding by means of this method is realized on multi-axes grinders numerically controlled. The direct method is applied for manufacturing half-side milling cutters and some of the drills, which can be formed by grinding wheels of simple profiles e.g. 1A1, 1V1, $4 \mathrm{Y} 1$, etc. The indirect method is used at grinding of twist drills of complex shapes, where it is required to obtain precise cutting edge geometry. Designing the process by means of indirect meth-

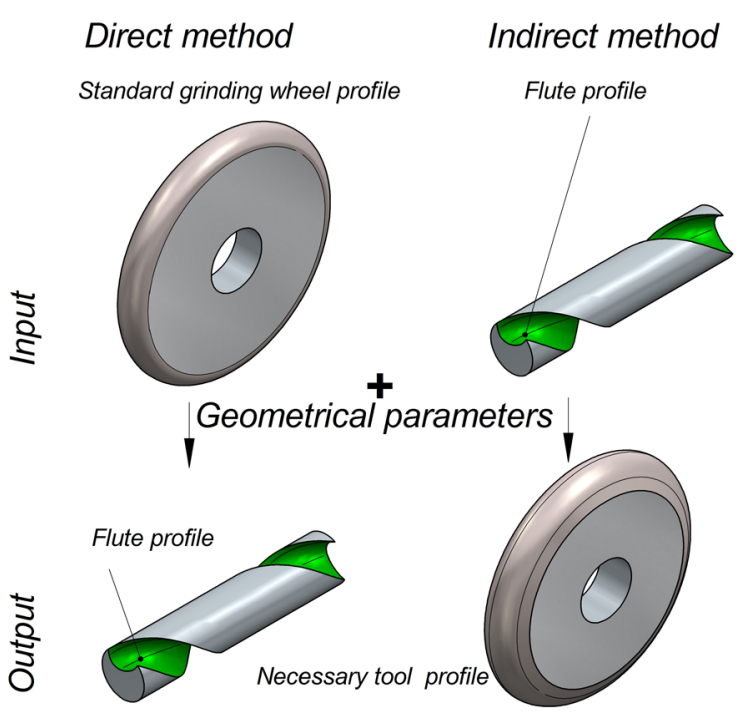

Fig. 2. Methods of shape, position and kinematics searching according to Kapruszchewski [5] 


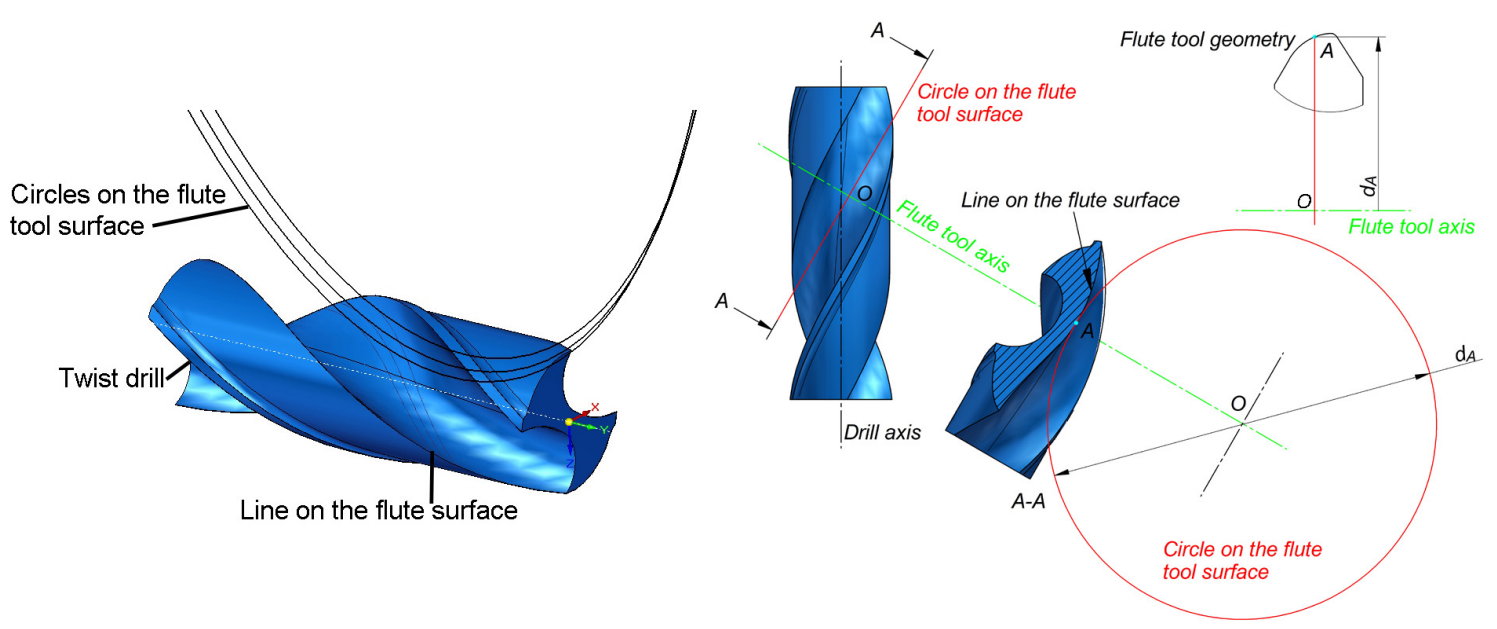

Fig. 3. Schema of determining tools outline for rolling of flute of twist drill

od, initial data are drill and flute geometrical parameters, yet, the exit data constitute the grinding wheel outline. By means of the indirect method is usually designed the grinding process realized on bi-axial grinders. Designing the process by the indirect method comes to determining the grinding wheel profile applying reverse engineering based on envelope theory [8].

Determining outline of tools for rolling of twist drills was based on indirect method. This solution is justified by the fact that tools for drills rolling can make only rotational motion during rolling. Hence, the correctness of the worked out process will depend only on tool shape and its placement in relation to the formed billet. The idea of determining tools outline for twist drills rolling is shown in Figure 3. Cheng and Yang highlighted that tools designing for twist drills rolling, similarly as in the case of tools for milling, consists of the following stages [3]:

- determining initial data,

- determining tool position in relation to machined material,

- determining geometry of rolled drill,

- determining tool profile surface.

The tool position in relation to the rolled product is limited by the applied rolling mill construction. After determining position of tool axis rotation in relation to the rolled product, further tangent circles to flute surfaces are determined. The number of circles determined on the flute width acts on precision of obtained tool profile. Sections determined from circles tangent to flute (e.g OA) of length corresponding to radii of these circles are deposited on the tool width. Connecting the following points of determined sections by curve

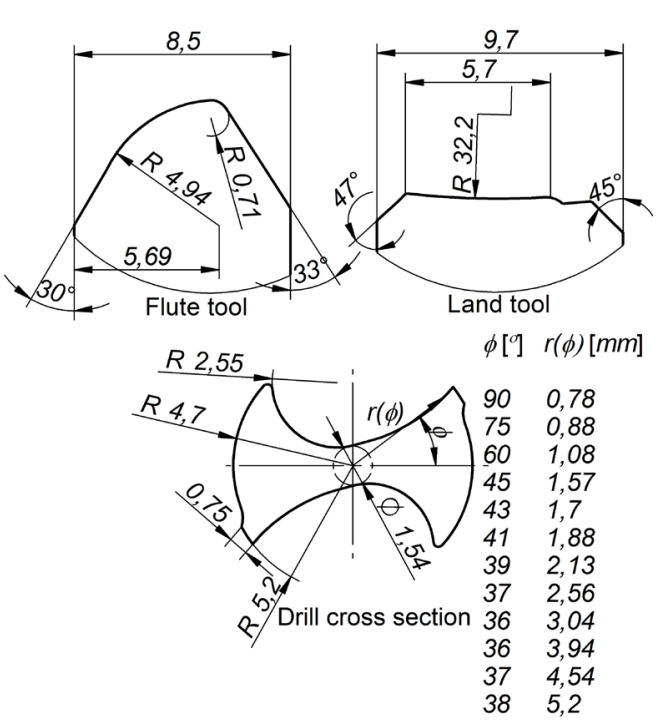

Fig. 4. Tools shape and cross section of rolled drill

B-spline the searched for tool profile is obtained. Determined graphically tools shape and cross-section of the rolled drill are shown in Figure 4.

\section{NUMERICAL MODELING}

Numerical modeling of the skew rolling process of twist drills was performed by means of finite element method applying software Simufact Forming in version 12.0.1. Numerical model of the twist drill rolling process of diameter $\varnothing 10$ $\mathrm{mm}$ that is built in this software was identical as the rolling schema shown in Figure 1. It was assumed at the stage of numerical model construction that the rolling process would be realized for the drill with inclination angle of helical line $\lambda=$ $30^{\circ}$. However, inclination angle of tools in rela- 
tion to the rolled billet was $33^{\circ}$. The rest of boundary conditions considered during numerical model construction are presented in Table 1. It was assumed in simulation that the holder has the possibility of free movement along the rolling axis and rotation around this axis. Flow curves of high-speed steel HS6-5-2 used in numerical simulation were taken from the applied software base. Rheology of the applied high-speed steel is described by the following equation:

$$
\sigma_{o}=3815.18 e^{(-0.0028 T)} \cdot \varepsilon^{(0.000417 T-0.675398)} \cdot e^{\left(\frac{0.0001 T-0.149}{\varepsilon}\right)} \cdot \dot{\varepsilon}^{(0.000226 T-0.107)}
$$

where: $\sigma_{\mathrm{o}}-$ flow stress, $\varepsilon$ - true strain, $\dot{\varepsilon}-$ strain rate, $\mathrm{T}-$ temperature.

Table 1. Assumed boundary conditions of the rolling process

\begin{tabular}{|c|c|}
\hline Boundary condition & Value \\
\hline Rolled material & steel HS6-5-2 \\
\hline Billet material dimensions & $\varnothing 10,2 \times 75 \mathrm{~mm}$ \\
\hline Tools material & rigid bodies \\
\hline Rolling initial temperature & $1050^{\circ} \mathrm{C}$ \\
\hline Tools temperature & $50^{\circ} \mathrm{C}$ \\
\hline Tools rotary velocity & $38 \mathrm{rot} / \mathrm{min}$ \\
\hline $\begin{array}{c}\text { Heat exchange coefficient; } \\
\text { billet-tool }\end{array}$ & $20 \mathrm{~kW} / \mathrm{m}^{2} \mathrm{~K}$ \\
\hline $\begin{array}{c}\text { Heat exchange coefficient; } \\
\text { billet-environment }\end{array}$ & $50 \mathrm{~W} / \mathrm{m}^{2} \mathrm{~K}$ \\
\hline Friction factor billet-tools & 0,85 \\
\hline Billet discretization & 375000 \\
tetragonal elements
\end{tabular}

On the basis of conducted numerical research, strains, temperatures and force parameters of the rolling process were determined.

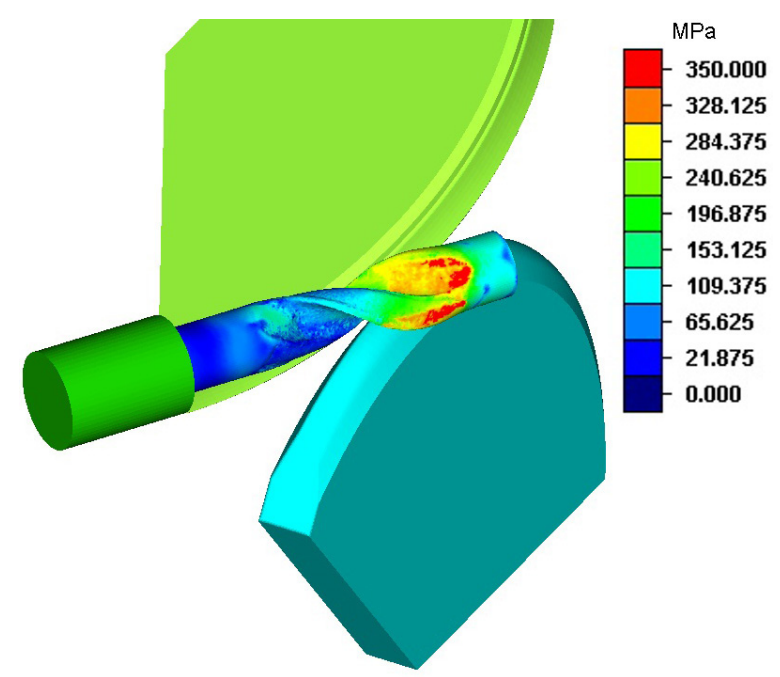

Fig. 5. Distribution of effective stresses (MPa) during rolling

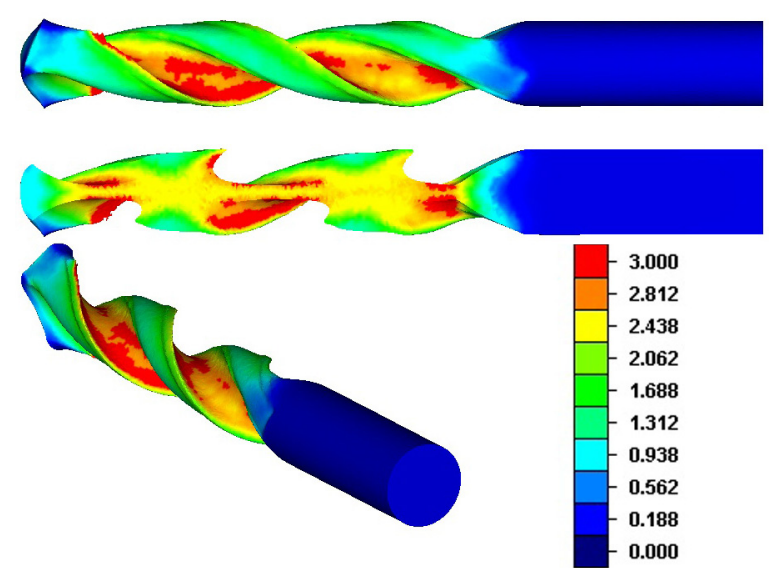

Fig. 6. Effective strain distribution in the rolled twist drill

\section{RESULTS OF NUMERICAL MODELING}

The performed numerical simulation of twist drills rolling allowed for observation of material flow during the process. Figure 5 shows the configuration segments and drill during the process course together with marked distribution of effective stress in the drill. From this Figure it can be seen that the designed segments give the drill appropriate shape. During the whole process flash presence, which may appear due to improper tools designing, was not observed. Maximal effective stresses in roll gap do not exceed the value of $400 \mathrm{MPa}$.

Figure 6 presents distribution of strain intensity for the formed twist drill. Maximal values of strain are localized near superficial area of flutes and in drill core. Relatively smaller values of strain can be observed in areas of drills blade. On the flutes surface larger values of strain are present on the side drill margin (the rake face of the flute).

Temperature distribution in the rolled drill is shown in Figure 7. This distribution proves 


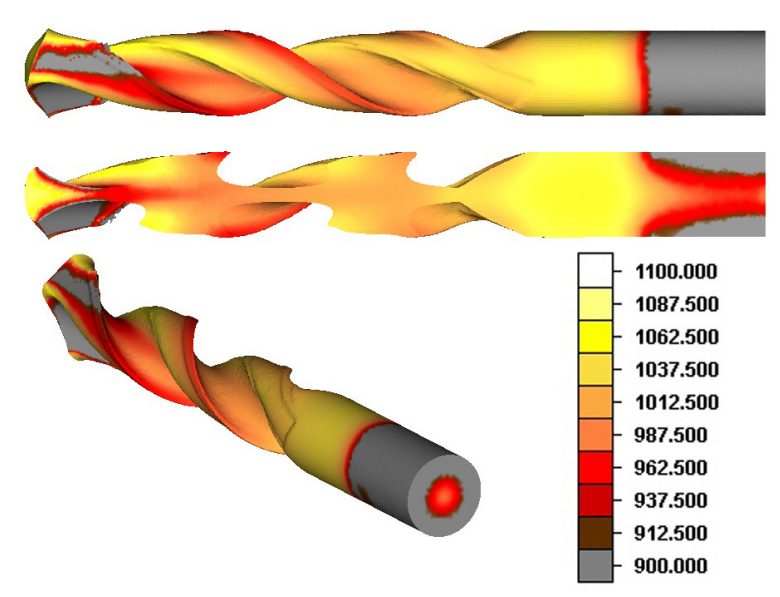

Fig. 7. Distribution of temperature $\left({ }^{\circ} \mathrm{C}\right)$ in rolled twist drill

that intensive cooling of material does not take place during rolling. Areas, in which the largest temperature decrease below $900^{\circ} \mathrm{C}$ was noticed, are present in the drill holder, which does not undergo rolling and in the area of direct contact of rolling segments with the material. In the case of the drill holder, temperature decrease in this area is not significant as this area does not undergo rolling. In real conditions this area is not heated at all. In order to simplify numerical modeling it was assumed that the rolled material was heated in the whole volume. Temperature decrease in the area of contact with tools is caused by large temperatures difference between rolled material and tools. The

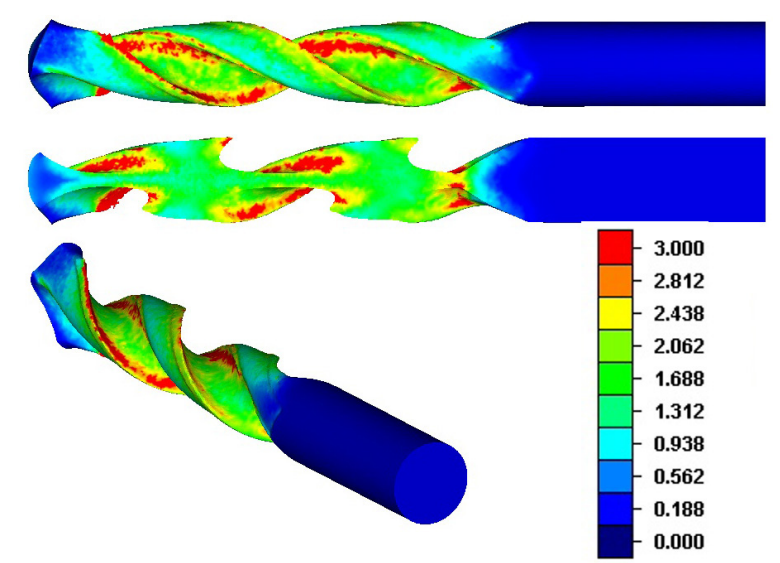

Fig. 8. Damage criterion distribution in rolled twist drill temperature in the rolled drill part is considerably larger than in the area of the roll gap. The increase of temperature in the rolled drill part is the effect of change of plastic deformation work and friction forces work into heat. The noticed temperature of the machined material comprises within the temperatures scope (900$1100^{\circ} \mathrm{C}$ ) rolling of high-speed steel HS6-5-2.

Figure 8 presents the distribution of normalized cracking criterion according to CockroftLatham. The given data shows that the largest possibility of material cohesion loss during rolling is at the drill's edges. A small increase of the damage criterion was also noticed on the flute surface. Numerically determined areas in which the risk of cracks is bigger remain in large convergence with real conditions. The most prone to cracks areas are the drill's edges. As Bennecke [1] reports, improper tools arrangement is the cause of cracks appearance on the rolled drills edges. Improper arrangements of segments leads to presence of too large slot between them. During rolling material is pressed into slots between segments, which creates too sharp drill's edges, on which cracks begin to appear.

Figure 9 shows the surface of contact of tools with rolled material in the stated state of the rolling process. The area of tools contact for rolling of land is definitely smaller than the area of tools contact for rolling of flutes. Differences of contact surface resulting from the process kinematics will be reflected in the rolling process force parameters. On the basis of observations of the contact surface it can be stated that in the skew rolling process of twist drills is present complex, special contact between tools and the formed material. In Figure 9 distribution of contact pressures is also presented. In both contact cases, the distribution of pressures is heterogeneous and the largest values of pressures are localized in

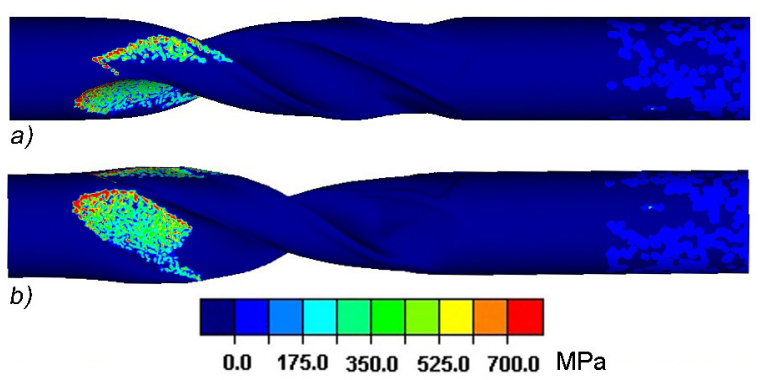

Fig. 9. Distribution of contact pressures: a) land forming tool, b) flute forming tool 
the input area into roll gap. In the area of flute larger contact pressures are localized at the back of the flute. In this case large contact pressures will be the cause of more intensive wear of tool segment in the part forming the back surface of the flute. Due to the fact that the back part of the flute is freely designed, too fast wear out of this segment part will not have such a significant influence on the rolled twist drills quality. Maximal contact pressures on the contact surface with tools for flutes reach quite large values equal approximately $700 \mathrm{MPa}$. However, in the case of contact with land forming tools maximal pressures reach about $600 \mathrm{MPa}$.

Presently used software FEM for numerical modeling of metal forming processes, apart from thermo-mechanical analysis, allows for foreseeing tools wear. For the analysis of tools wear by means of finite element method various types of analytical models are applied. The most frequently applied wear models are: Archard, Usui and Finnie. Archard's wear model is ideal for discretization of cold and hot metal forming processes, where dominant wear of forming tools is abrasive. Numerically determined distribution of wear according to Archard model in the process of twist drills rolling is shown in Figure 10. In numerical simulation assumed that tools are made from tool steel of hardness 60 HRC.

Although contact pressure was favorable, definitely larger tools for flutes rolling wear is at the side responsible for forming of rake face

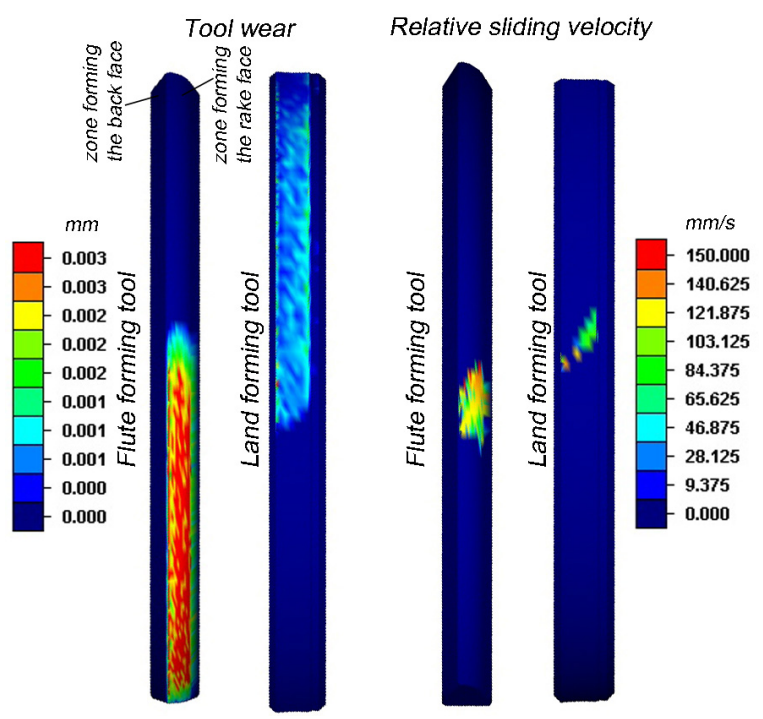

Fig. 10. Distribution of tools wear and relative sidle velocity

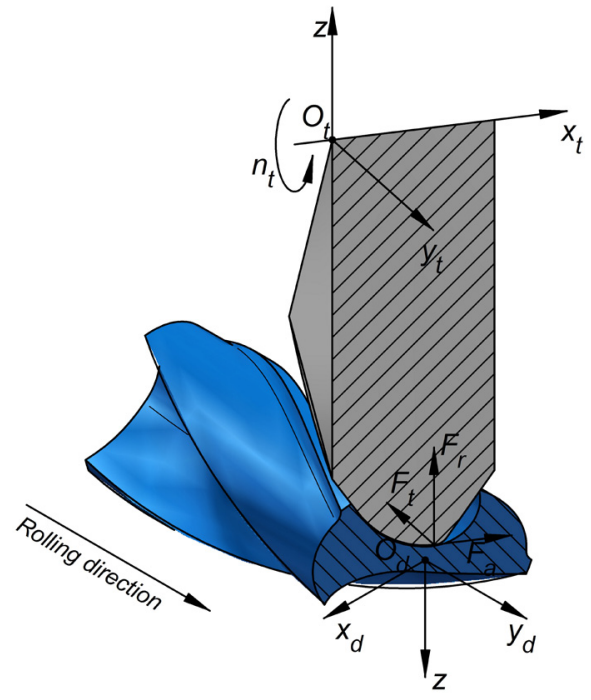

Fig. 11. Distribution of forces acting on segment during rolling in tool coordinate system $\left\{\mathrm{o}_{\mathrm{t}}: \mathrm{x}_{\mathrm{t}}, \mathrm{y}_{\mathrm{t}}, \mathrm{z}\right\}$

of flute. The increased wear of this side of segment is the result of metal slide. In the analyzed case the relative velocity of metal slide on the segment part forming rake face of flutes equals about $140 \mathrm{~mm} / \mathrm{s}$. Smaller wear takes place in the case of segment for rolling of lands. This is the result of smaller surface pressure and considerably smaller slide velocity during rolling. Large slide velocity of metal in relation to flute is also the cause of redundant strain appearance in the formed material, which is confirmed by shown in Figure 6 distribution of effective strain. The presented in Figure 10 distribution of depth of abrasive wear considers the case of rolling of one piece of drill.

One of the main advantages of numerical modeling is the possibility of initial estimation with quite large precision the energetic parameters of the process. The knowledge of these parameters at the technology designing stage is important as it allows for choosing the machine, which will be able to guarantee realization of the worked out process. Figure 11 shows the distribution of forces acting on segment during skew rolling of twist drills. During rolling at a given stage of the process, tool segment is loaded by: axial force $\mathrm{F}_{\mathrm{a}}$; acting along axis $\mathrm{x}_{\mathrm{t}}$, radial force $\mathrm{F}_{\mathrm{r}}$; acting along axis $\mathrm{z}$ and tangent force $\mathrm{F}_{\mathrm{t}}$; acting along axis $y_{t^{\circ}}$.

Numerically determined course of rolling moment is shown in Figure 12. According to assumptions, the rolling moment assumes larger values for the tool forming the drill flute. The 


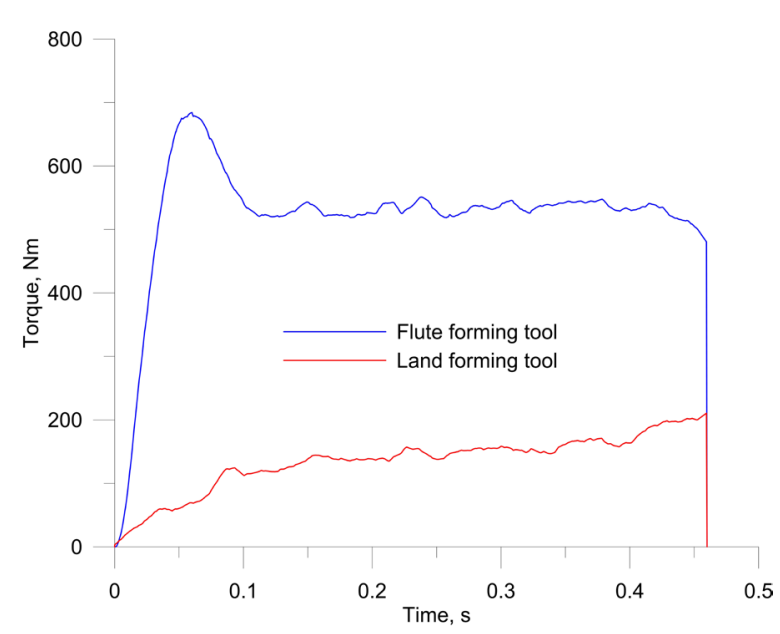

Fig. 12. Course of rolling moment in the analyzed process

moment value at stated phase of the process for the flute segment is almost 3.5 times larger than moment noticed for the land segment. At the beginning of the process, the moment noticed for the flute segment rapidly increases assuming temporary value at the level $700 \mathrm{Nm}$. In the further stage of the process, the moment remains at the constant level equal about $550 \mathrm{Nm}$. The increase of the moment at the process beginning is connected with flute tool penetrating the formed material. In the case of land tool the moment at the beginning of forming increases slowly assuming the stated value $15 \mathrm{Nm}$ in 1.3 second of the process course. At the end of the process a small increase of the rolling moment noticed at land segment can be observed, which is the result of larger material widening by flute segments at the end of rolling. Determined val-

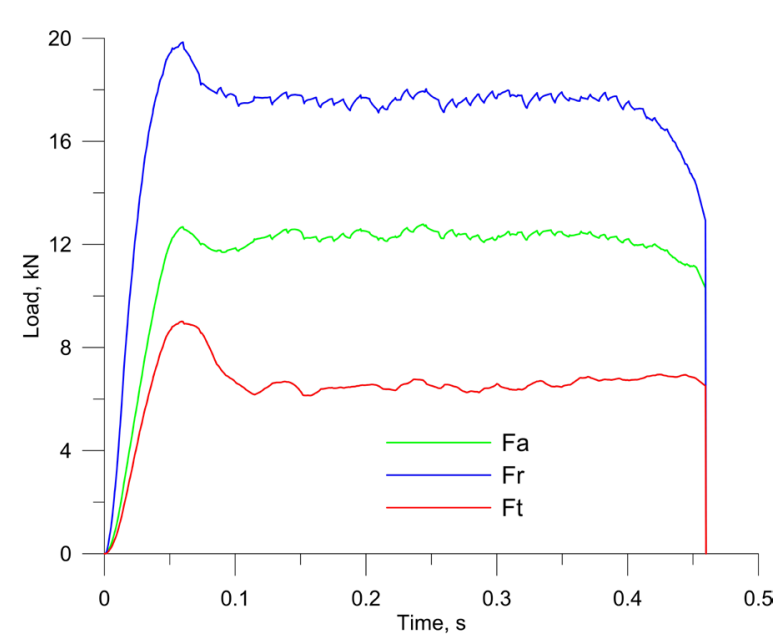

Fig. 13. Distribution of forces for flute segment ues of the rolling moments are considerably smaller, hence it is not required to apply in machines for twist drills rolling large engines.

Force characteristics of the process of twist drills rolling are presented in Figure 13 and Figure 14. Similarly, as in the rolling moment, forces on tools segments are relatively small although high-speed steel is difficult to form. In the case of flute segment the largest values assumes radial force $F_{r}$, yet, the smallest values assumes tangent force $\mathrm{F}_{\mathrm{t}}$. In the case of land segment also the largest values assumes radial force $\mathrm{F}_{\mathrm{r}}$, however, the smallest values are present in the direction of axial force acting $F_{a}$. In the case of land segment in the moment of material grasping axial force $\mathrm{F}_{\mathrm{a}}$ assumes larger values than tangent force $\mathrm{F}_{\mathrm{t}}$. During stated rolling phase the flute segment is loaded in axial direction more than the land segment, which is caused by the rolled material twisting. The drill during twisting causes definitely larger flute segment loading in axial direction than land segment. Similarly, as in the force rolling moment, radial $F_{r}$ and tangent $F_{t}$ loading the land segment at the end of rolling increase. This is the result of the enlarged widening of material at the end of the process, which is visible in Figure 6-8.

\section{CONCLUSIONS}

This paper presents thermo-mechanical analysis of the skew rolling process of a twist drill of diameter $\varnothing 10 \mathrm{~mm}$. Numerical simulation was conducted by means of finite element

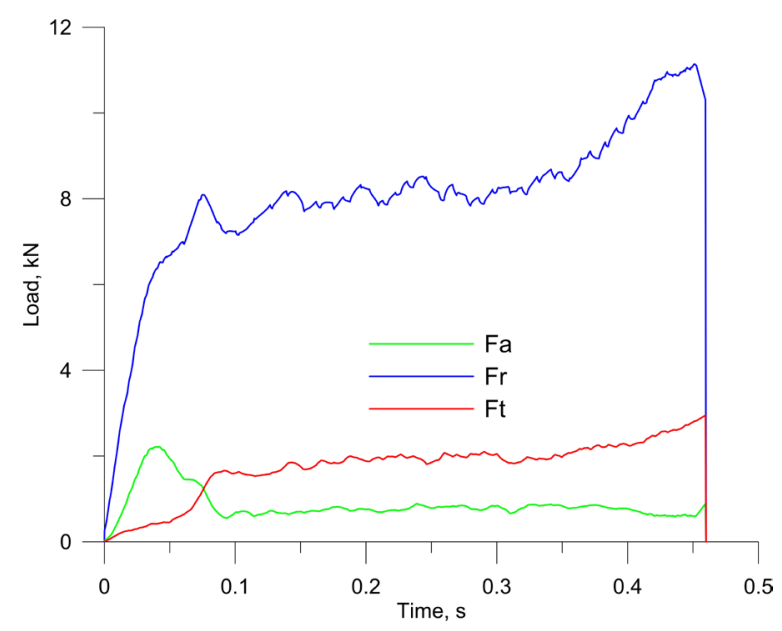

Fig. 14. Distribution of forces for land segment 
method with the application of software Simufact. Forming. The constructed numerical model of the rolling process complied with the rolling process realized in machine type WS in terms of kinematics and geometry. The indirect way of tools designing for rolling of twist drills based on graphic method with application of envelope theory was presented. The realized numerical simulation confirmed the usefulness of the indirect method of tools designing for skew rolling. On the basis of the performed numerical simulation it was stated that in the skew rolling process heterogeneous strain distribution is present. During the process course, the formed material does not undergo excessive cooling, which could limit the process realization. In the skew rolling process of twist drills contact pressures are uneven and their value can reach $700 \mathrm{MPa}$. Flute segments undergo larger abrasive wear during rolling. Intensive tools wear appears at the segment surface responsible for forming of rake face of flute. The skew rolling process takes place at relatively small values of forces and rolling moments. Positive results of the conducted numerical simulation confirm the usefulness of finite element method for the analysis and designing of the skew rolling process of twist drills.

\section{REFERENCES}

1. Bennecke R. Einige Fehlerursachen beim Drallwalzen von Spiralbohrern aus Schnellarbeitsstählen. Thyssen Edelstahl Technische Berichte, 2(3), 1977, 105-110.

2. Bulzak T., Tomczak J. and Pater Z. Method for producing twist drills by extrusion using a threeslide forging press. Key Engineering Materials, 622-623, 2014, 129-135.

3. Chen J. and Yang R. Profile design of the helical groove milling tool. Advanced Materials Research, 706-708, 2013, 1496-1499.

4. Ivanov V. and Nankov G. Profiling of rotation tools for forming of helical surfaces. International Journal of Machine Tools and Manufacture, 38, 1998, 1125-1148.

5. Karpuschewski B., Jandecka K. and Mourek D. Automatic search for wheel position in flute grinding of cutting tools. CIRP Annals - Manufacturing Technology, 60, 2011, 347-350.

6. Smith T.G. Cutting Tool Technology. Springer, 2008.

7. Zhang Q.S. Screw Groove Rolling Technology. Mechanical Industry Press, 1985.

8. Zhang W., Wang X., He F. and Xiong D. A practical method of modelling and simulation for drill fluting. International Journal of Machine Tools and Manufacture, 46(6), 2006, 667-672. 